Disclosure of Interests: Laura C Coates Grant/research support from: AbbVie, Celgene, Lilly, Novartis and Pfizer, Consultant for: AbbVie, Amgen, BMS, Celgene, Galapagos, Gilead Sciences Inc., Janssen, Lilly, Novartis, Pfizer, Prothena Corp and UCB, Alexis Ogdie Grant/research support from: (To my university) Novartis, Pfizer, Grant/research support from: Novartis, Pfizer, Grant/research support from: Novartis, Pfizer, Grant/ research support from: Novartis, Pfizer, Consultant for: AbbVie, BristolMyers Squibb, Celgene, Corrona, Eli Lilly and Company, Novartis, Pfizer, and Takeda, Consultant for: AbbVie, Amgen, Bristol-Myers Squibb, Celgene, Corrona, Eli Lilly, Novartis, Pfizer Inc, Takeda, Consultant for: Abbvie, Amgen, BMS, Celgene, Corrona, Lilly, Novartis, Pfizer, Takeda, Consultant for: Abbvie, Amgen, BMS, Celgene, Corrona, Lilly, Novartis, Pfizer, Takeda, Prashanth Sunkureddi Shareholder of: Pfizer, Johnson and Johnson, Mallinckrodt, Regeneron, Grant/research support from: Clinical research trials for Eli Lilly, Novartis, Amgen, Pfizer, Consultant for: Eli Lilly, Novartis, AbbVie, Pfizer, Speakers bureau: Eli Lilly, Novartis, AbbVie, Sanofi Genzyme, Regeneron, Pfizer, Lisa Kerr Shareholder of: Eli Lilly and Company, Employee of: Eli Lilly and Company, Matthew Hufford Shareholder of: Eli Lilly and Company, Employee of: Eli Lilly and Company, Philip Helliwell Grant/research support from: Paid to charity: from AbbVie, Janssen and Novartis, Consultant for: Paid to charity: from AbbVie, Amgen, Pfizer, and UCB and Celgene. Paid to self: from Celgene and Galapagos

DOI: 10.1136/annrheumdis-2019-eular.1225

\section{FRI0427 IS THE CLINICAL AND THERAPEUTIC PROFILE RELATED TO SATISFACTORY RESPONSE TO APREMILAST IN PSORIATIC ARTHRITIS?}

Isabel de la Morena ${ }^{1}$, María Espinosa ${ }^{2}$, Hilda Godoy Tunidor ${ }^{3}$, À Martínez-Ferrer ${ }^{4}$, Carlos Santos Ramirez ${ }^{5}$, Anna Martinez ${ }^{6}$, Meritxell Fernandez Matilla ${ }^{7}$, Nagore Fernández-Llanio ${ }^{7}$, Deseada Palma Sanchez ${ }^{8}$, Maria Jose Moreno ${ }^{8}$ Ana Haro ${ }^{8}$, Arantxa Conesa ${ }^{9}$, Javier Calvo ${ }^{10} .{ }^{1}$ Hospital Clinico Universitario de Valencia, Valencia, Spain; ${ }^{2}$ Hospital Puerta de Hierro, Madrid, Spain; ${ }^{3}$ Hospital Puerta de Hierro, Rheumatology, Madrid, Spain; ${ }^{4}$ Hospital Doctor Peset, Rheumatology, Valencia, Spain; ${ }^{5}$ Hospital Virgen de los Lirios, Alcoy, Spain; ${ }^{6}$ Hospital de la Ribera, Rheumatology, Alzira, Spain; ${ }^{7}$ Hospital Arnau de Vilanova, Valencia, Spain; ${ }^{8}$ Hospital Rafael Mendez, Lorca, Spain; ${ }^{9}$ Hospital General de Castellón, Castellón, Spain; ${ }^{10}$ Hospital General Universitario de Valencia, Valencia Spain Objectives: To identify the factors that are related with response to Apremilast(APR) in Psoriatic Arthritis(PsA).

Methods: An observational and analytical multicenter retrospective study. There are included PSA patients treated with APR after two years of commercialization. Clinical and demographic data were collected: disease duration, previous treatments, cutaneous and joint involvement pattern defined as: joint exclusively, non joint and mixed (by several domains combination). It was collected: duration of treatment, tolerance, adverse events, and reason for APR choice: intolerance or toxicity to cSDMARD, preference before bDMARD contraindication or caution to bDMARD, CSDMARD and bDMARD inefficacy, cSDMARD and bDMARD intolerance. The effectiveness was considered as a dicotomic variable (Yes/No) by clinical criteria.

Results: There were included 89 patients, 46(51.7\%) males, the mean age was $53.99 \pm 12.3$ years, and the PsA disease duration was $7.28 \pm 6.25$ years. The PsA pattern was: joint 29(32.6\%), non joint, 12(13.5\%) and mixed $48(53.9 \%)$. The reason for APR choice was: intolerance or toxicity to CDMARD 13 patients, preference before BT 28, contraindication or caution to BT 22, inefficacy to CDMARD or BT 18, intolerance to CDMARD and BT 1, and due to clinical profile 1. After a mean treatment duration with APR of $8.13(0-23)$ months a total of 33 withdrawals were found (17 due to inefficacy and 16 due to intolerance), treatment was mantained on them a mean of $4.3(0-12)$ months. 56 patients keep with APR a mean of $10.4(2-23)$ months, 22 of them among 1 and 2 years of evolution. The treatment was effective in $61(68.5 \%)$ patients. Comparisons of the different variables analyzed did not show significative differences among the responders and non responders patients.

Conclusion: We have not found a specific profile that relates with a satisfactory response to APR.

Disclosure of Interests: Isabel de la Morena Speakers bureau: Abbvie, Celgene, Pfzier, UCB, Ghebro, Roche, Sanofi, Janssen., María Espinosa: None declared, Hilda Godoy Tunidor: None declared, À Martínez-Ferrer: None declared, Carlos Santos Ramirez: None declared, Anna Martinez: None declared, Meritxell Fernandez Matilla: None declared, Nagore Fernández-Llanio: None declared, DESEADA PALMA SANCHEZ: None declared, Maria jose Moreno: None declared, Ana HARO : None declared, Arantxa Conesa: None declared, Javier Calvo Consultant for: Abbvie, Celgene, Pfzier, UCB, Ghebro, Roche, Sanofi, Janssen, Novartis,
Amgen., Speakers bureau: Abbvie, Celgene, Pfzier, UCB, Ghebro, Roche, Sanofi, Janssen, Novartis, Amgen.

DOI: 10.1136/annrheumdis-2019-eular.8099

\section{FRI0428 PSORIATIC ARTHRITIS AND DEPRESSIVE SYMPTOMS: DOES SYSTEMIC INFLAMMATION PLAY A ROLE?}

Enrico De Lorenzis ${ }^{1}$, Gerlando Natalello ${ }^{1}$, Dario Bruno ${ }^{1}$, Giacomo Tanti ${ }^{1}$, Giovanni Battista Canestrari ${ }^{1}$, Maria Rosaria Magurano ${ }^{2}$, Clara DI Mario ${ }^{1}$, Barbara Tolusso ${ }^{3}$ Giusy Peluso ${ }^{3}$, Elisa Gremese ${ }^{1,3} .{ }^{1}$ Catholic University of the Sacred Heart, Institute of Rheumatology, Rome, Italy, ${ }^{2}$ Fondazione Policlinico Universitario A. Gemelli IRCCS, Department of Psychology, Rome, Italy, ${ }^{3}$ Fondazione Policlinico Universitario A. Gemelli IRCCS, Department of Rheumatology, Rome, Italy

Background: Depression is one of the most common comorbidities in patients with Psoriatic Arthritis (PsA) but risk factors for mood disorders in these patients are still largely unrecognized. Pro-inflammatory cytokines involved in the pathogenesis of PsA have been also associated with depressive symptoms in patients without systemic autoimmune diseases. Objectives: The aim of this study is to determine risk factors for depressive symptoms and compare serum cytokines concentrations in subjects with and without depressive symptoms in a court of PsA patients.

Methods: Eighty consecutive patients with PsA were screened for depressive symptoms with depression subscale of the Hospital Anxiety and Depression Scale (HADS-D). A validated cut-off of 8 was used to define patients with significative depressive mood. Patients with and without depressive symptoms were compared for the prevalence of general risk factors for depression, comorbidity, psoriatic disease age of onset, duration, activity and domains affected, treatment and serum levels of IL-6, TNF- $\alpha$ and IL-17A.

Results: Mean disease duration of skin disease and articular disease was $18.8 \pm 15.3$ years and $9.0 \pm 11.1$ years, respectively. All patients had a history of peripheral arthritis, $41.3 \%$ had dactylitis, $38.8 \%$ had enthesitis, $21.3 \%$ had spondylitis $82.5 \%$ had a psoriatic skin disease and $51.2 \%$ had psoriatic nail disease. According to DAPSA index, $20.0 \%$ were in remission, $50.0 \%$ in Low Disease Activity, $20.0 \%$ in Moderate Disease Activity and $10.0 \%$ in High Disease Activity. Thirty-five (43.8\%) were in Minimal Disease Activity. Thirty-three patients (41.3\%) had depressive symptoms according to HADS. Patients with and without depressive symptoms did not differ in terms of age, gender, comorbidity general risk factors of depression, psoriatic disease age of onset, duration, domains affected, DAPSA activity, MDA achievement, PASI, HAQ, VAS pain, the intensity of treatment, serum TNF- $\alpha$ IL-17A and IL-23. Serum levels of IL-6 were higher in patients with depressive symptoms $(2.99 \pm 2.58$ vs $1.54 \pm 1.60 \mathrm{pg} / \mathrm{dl} ; \mathrm{p}=0.006)$. A cut-off of $2.27 \mathrm{pg} / \mathrm{ml}$ of serum IL-6 had the best ability to predict a HADS $\geq 8$ according to higher Youden Index of the ROC curve (AUC 0.682 $\pm 0.061 ; \mathrm{p}=0.006$ ). Multivariate logistic regression analysis revealed that serum $\mathrm{IL}-6 \geq 2.27 \mathrm{pg} / \mathrm{ml}$ was a predictor of depressive symptoms even when adjusted for DAPSA, HAQ and PASI (OR 3,06; CI 1.14-8.20; $\mathrm{p}=0.026$ ).

Conclusion: Higher serum II-6 is associated with depressive symptoms independently from articular and cutaneous disease activity and degree of disability. This association suggest a direct role of systemic inflammation in the modulation of mood in PsA patients.

\section{REFERENCES}

[1] Husni ME, et al. The psychosocial burden of psoriatic arthritis. Semin Arthritis Rheum 2017

[2] Ogata A, et al. Pathological Role of Interleukin-6 in Psoriatic Arthritis Arthritis 2012.

[3] Hodes GE et al. Integrating Interleukin-6 into depression diagnosis and treatment. Neurobiol Stress 2016.

[4] Zigmond AS et al. The Hospital Anxiety and Depression Scale. Acta Psychiatr Scand 1983.

Disclosure of Interests: Enrico De Lorenzis: None declared, Gerlando Natalello: None declared, Dario Bruno: None declared, Giacomo Tanti: None declared, Giovanni Battista Canestrari: None declared, Maria Rosaria Magurano: None declared, Clara Di Mario: None declared, Barbara Tolusso: None declared, Giusy Peluso: None declared, Elisa Gremese Consultant for: AbbVie, BMS, Celgene, Janssen, Lilly, MSD, Novartis, Sanofi, UCB, Roche, and Pfizer, Speakers bureau: BMS, Speakers bureau: Roche, Speakers bureau: AbbVie, BMS, Celgene, Janssen, Lilly, MSD, Novartis, Sanofi, UCB, Roche, and Pfizer DOI: 10.1136/annrheumdis-2019-eular.6426 